\title{
HUBUNGAN PENDIDIKAN DAN PERSEPSI DENGAN KEIKUTSERTAAN PRENATAL YOGA PADA IBU HAMIL
}

\author{
Ni Wayan Manik Parwati1, Idah Ayu Wulandari \\ ${ }^{1,2}$ STIEKES Bali Renon Bali
}

(Korespondensi: manikparwati82@gmail.com)

\begin{abstract}
ABSTRAK
Pendahuluan. Kehamilan merupakan suatu proses yang fisiologi bagi seorang wanita, tetapi tidak semua proses kehamilan dapat berjalan dengan normal, karena selama kehamilan terjadi adaptasi anatomi, fisiologi dan biokimiawi yang terus meningkat sejalan dengan usia kehamilan. Metode: Penelitian ini menggunakan design analitik korelasi dengan pendekatan cross sectional. Sampel dalam penelitian adalah ibu hamil yang memenuhi kriteria inklusi sebanyak 124 responden. Alat pengumpulan data adalah kuesioner. Analisis bivariat dengan uji korelasi Chi Square. Hasil dan analisis: Analisis bivariat antara pendidikan dan persepsi, memiliki hubungan yang signifikan dengan keikutsertaan dalam prenatal yoga, semua variabel memiliki nilai $\mathrm{p}$ value < 0,001 . Diskusi. Pendidikan, persepsi, memiliki hubungan yang signifikan dengan keikutsertaan dalam prenatal yoga.
\end{abstract}

Kata kunci : pendidikan, persepsi, prenatal yoga

\begin{abstract}
Introduction. Pregnancy is a physiological process of a woman, but not all pregnancy processes can run normally, because during pregnancy there is an anatomic, physiological and biochemical adaptation that continues to increase with gestational age. Method. This research uses correlation analytic design with cross sectional approached. The sample of the study was pregnant women who met that inclusion criteria as many as 124 respondents. The data collection tool is a questionnaire. Bivariate analysis with Chi Square correlation tested. Results. Bivariate analysis between education and perception has a significant relationship with participation in prenatal yoga's, all variables have a $p$ value of $<0.001$. Discussion. Education and perception have a significant relationship with participation in prenatal yoga's
\end{abstract}

Keywords: education, perception, prenatal yoga's 


\section{PENDAHULUAN}

Kehamilan merupakan suatu kodrati serta proses yang fisiologi bagi seorang wanita, tetapi tidak semua proses kehamilan dapat berjalan dengan normal, karena selama kehamilan terjadi adaptasi anatomi, fisiologi dan biokimiawi yang terus meningkat sejalan dengan usia kehamilan. Kehamilan dapat mengakibatkan stres yang meningkat bagi tubuh ibu karena harus mengakomodasi penambahan kebutuhan energi untuk janin yang sedang berkembang. Oleh karena itu, beberapa perubahan fisiologis dan metabolisme berlangsung dalam tubuh ibu untuk beradaptasi dengan kondisi tersebut, tetapi terkadang dalam proses adaptasi dapat terjadi komplikasi yang membahayakan bagi ibu maupun janin bahkan dapat menyebabkan kematian.

Ibu hamil harus mendapat asuhan kehamilan agar dapat beradaptasi dengan perubahan yang terjadi baik fisik maupun psikologinya. Tujuan asuhan selama masa kehamilan untuk mempersiapkan persalinan yang fisiologis dengan tujuan ibu dan janin yang akan dilahirkan dalam keadaan sehat (Kemenkes RI, 2009). Metode untuk meringankan dan membantu ibu hamil dalam persiapan persalinan adalah dengan olahraga yang bertujuan untuk menjaga kesehatan tubuh dan janin agar berkembang dengan baik dan juga membuat emosi ibu tetap stabil.

Salah satu latihan olah tubuh yang baik untuk wanita hamil adalah Yoga. Latihan Yoga merupakan latihan olah tubuh, pikiran dan mental yang menggabungkan beberapa tehnik yaitu pernafasan (Pranayama), position (Asana), Meditasi dan Relaksasi (Shindu, 2013). Latihan Yoga baik dilakukan setelah bulan keempat atau pada trimester kedua karena kondisi kandungan sudah stabil dan kuat (Rusmita, 2011).

Adapun tujuan dari penelitian ini untuk menganalisis faktor-faktor yang berhubungan dengan keikutsertaan prenatal yoga pada ibu hamil, yaitu faktor pendidikan dan persepsi.

\section{METODE}

Jenis penelitian ini adalah analitik korelasi dengan pendekatan cross sectional. Populasi dalam penelitian ini adalah seluruh ibu hamil yang periksa 
kehamilan di Puskesmas III Denpasar Utara selama bulan Maret-April 2019. Teknik sampling yang digunakan adalah accidental sampling. Dalam penelitian ini sampel yang diambil telah memenuhi kriteria inklusi yang telah ditetapkan oleh peneliti. Jumlah sampel adalah 124 responden.

Dalam penelitian ini pengumpulan data dengan menggunakan kuisioner. Data yang dikumpulkan berupa data primer yang diperoleh secara langsung oleh peneliti yaitu pendidikan, persepsi dan keikutsertaan prenatal yoga. Data yang dikumpulkan diolah dan dianalisis secara univariat dan bivariat. Analisis dengan Chi Square (x2) dan tingkat kemaknaan $\mathrm{p}<0,05$ untuk melihat ada atau tidaknya hubungan variabel bebas dan varibel terikat.

\section{HASIL PENELITAN}

Penelitian ini dilakukan di Puskesmas III Denpasar Utara dengan jumlah responden pada penelitian ini adalah 124 Ibu Hamil. Gambaran karakteristik ibu hamil di Puskesmas III Denpasar Utara berdasarkan Umur, Paritas dan
Status Pekerjaan. Karakteristik responden disajikan dalam Tabel 1

Tabel 1

Karakteristik Repsonden di

Puskesmas III Denpasar Utara

\begin{tabular}{lll}
\hline Karakteristik & n & $\%$ \\
Responden & &
\end{tabular}

$\begin{array}{lll}\text { Umur } & & \\ \text { 20-35 tahun } & 114 & 91.9 \\ >35 \text { tahun } & 10 & 8.1\end{array}$

Paritas

$1 \quad 45 \quad 36.3$

$2 \quad 56 \quad 45.2$

$3 \quad 21 \quad 16.9$

$\begin{array}{lll}4 & 2 & 1.6\end{array}$

Status Pekerjaan

Bekerja $\quad 68 \quad 54.8$

Tidak Bekerja $\quad 56 \quad 45.2$

Berdasarkan distribusi frekuensi karakteristik ibu hamil di Puskesmas III Denpasar Utara didabatkan hasil bahwa 

35 tahun atau resti umur yaitu sebanyak $8,1 \%$, sebanyak $45,2 \%$ ibu hamil anak kedua dan sebagian besar ibu bekerja $(54,8 \%)$.

Deskripsi Pendidikan dan Persepsi Keikutsertaan Yoga pada Responden

Deskripsi pendidikan, persepsi dan keikutsertaan prenatal yoga pada responden diuraikan pada Tabel 2. ibu hamil dengan umur yang lebih dari

\begin{tabular}{lll}
\hline \multicolumn{1}{c}{ Variabel } & n & \% \\
\hline Pendidikan & & \\
Tidak Sekolah & 0 & 0 \\
SD & 39 & 31.5 \\
SMP & 39 & 31.5 \\
SMA & 46 & 37.1 \\
PT & 0 & 0 \\
Persepsi & & \\
$\quad$ Positif & 76 & 61.3 \\
$\quad$ Negatif & 48 & 38.7 \\
Keikutsertaan & & \\
Prenatal Yoga & 69 & 55.6 \\
$\quad$ Ikut Serta & 55 & 44.4 \\
Tidak Ikut Serta & & \\
\hline
\end{tabular}

Berdasarkan data diatas responden lebih

Tabel 2 Deskripsi Pendidikan, Persepsi, dan Keikutsertaan Prenatal Yoga banyak mengikuti prenatal yoga yaitu sebanyak 55.6\%, Responden di Puskesmas III Denpasar Utara juga lebih banyak memiliki persepsi yang positif terhadap prenatal yoga. Pendidikan terbanyak dari responden adalah SMA yaitu sebanyak $37.1 \%$. 
Analisis Bivariat antara Pendidikan dan Persepsi dengan Keikutsertaan Prenatal Yoga

Hubungan antara Analisis Bivariat antara Pendidikan dan Persepsi dengan Keikutsertaan Prenatal Yoga dianalisis dengan menggunakan analisis bivariate. Analisis bivariate yang digunakan adalah uji chi square. Hasil analisis bivariate dijabarkan pada Tabel 3

Tabel 3

Hasil Analisis Bivariat

Pendidikan dan Persepsi dengan

Keikutsertaan Prenatal Yoga

\begin{tabular}{clll}
\hline Variabel & \multicolumn{2}{l}{$\begin{array}{l}\text { Keikutsertaan Prenatal } \\
\text { Yoga }\end{array}$} & \\
& \multicolumn{2}{l}{$\mathbf{p}$} & \\
& $\begin{array}{l}\text { Ikut } \\
\text { Serta }\end{array}$ & $\begin{array}{l}\text { Tidak } \\
\text { Serta }\end{array}$ & \\
\hline Pendidikan & & & \\
SD & $5(12.8)$ & $34(87.2)$ & $<0,001$ \\
SMP & $24(61.5)$ & $15(38.5)$ & \\
SMA & $40(87)$ & $6(13)$ & \\
Persepsi & & & \\
Positif & $67(88.2)$ & $9(11.8)$ & $<0,001$ \\
Negatif & $2(4.2)$ & $46(95.8)$ & \\
& & &
\end{tabular}

Tabel 3 menunjukkan analisis bivariate antara pendidikan dan persepsi memiliki hubungan yang signifikan dengan keikutsertaan dalam prenatal yoga, semua variabel memiliki nilai $\mathrm{p}$ value < 0,001 .

\section{PEMBAHASAN}

\section{Hubungan Tingkat Pendidikan}

Dengan Keikutsertaan Prenatal Yoga

\section{Pada Ibu Hamil}

Pendidikan adalah suatu usaha manusia untuk meningkatkan ilmu pengetahuan, yang didapat dari lembaga formal maupun non formal. Menurut Notoatmodjo (2012) bahwa faktor pendidikan formal berpengaruh terhadap pengetahuan seseorang dalam menerima informasi. Hubungan tingkat pendidikan ibu hamil dengan keikutsertaan dalam prenatal yoga dalam penelitian ini dilihat dari hasil korelasi yang didapatkan nilai $\mathrm{p}<0,001$ maka Ha diterima dan Ho ditolak yang berarti terdapat hubungan. Hubungan pendidikan dengan keikutsertaan prenatal yoga pada ibu hamil diperkuat oleh data bahwa dari 46 responden yang berpendidikan SMA sebanyak 87\% mengikuti prenatal yoga, dari 39 
responden berpendidikan SMP sebanyak $61,5 \%$ mengikuti prenatal yoga dan 39 responden yang berpendidikan SD hanya $12,8 \%$ yang mengikuti prenatal yoga. Data menunjukkan semakin tinggi pendidikan maka keikutsertaan prenatal yoga juga meningkat. Adanya hubungan antara tingkat pendidikan dengan minat didasari oleh beberapa faktor yaitu faktor pendidikan responden hanya sampai pendidikan menengah. Tingkat pendidikan dapat mempengaruhi minat karena pendidikan mempengaruhi besarnya pengetahuan, yang mana pengetahuan adalah hasil setelah orang melakukan penginderaan terhadap suatu objek tertentu. Dalam hal ini objek yang dimaksud yaitu keikutsertaan prenatal yoga yang dipengaruhi oleh pengetahuan yang berupa dampak ketika mengikuti prenatal yoga. Minat dipengaruhi oleh pendidikan melalui pengetahuan.

Secara teori yang dikemukakan oleh Notoadmodjo pada Irianti (2017), semakin bertambah usia ibu, semakin bertambah pula tingkat kematangan dan kekuatan seseorang dalam berpikir dan bekerja. Namun faktor usia bukanlah faktor satu-satunya yang berhubungan dengan kepatuhan. Meskipun usia ibu bertambah, namun apabila tidak diikuti dengan kenaikan tingkat pendidikan hanya akan membuat ibu semakin kesulitan memperoleh informasi. Ibu yang berpendidikan rendah akan bersikap lebih acuh dan tidak memahami pentingnya prenatal yoga. Hasil penelitian Irianti (2014) dan Wulandari (2015), menyatakan semakin tinggi pendidikan ibu, maka semakin mudah ibu mendapatkan informasi. Seseorang dengan tingkat pendidikan yang rendah cenderung lebih tertutup dan lebih sulit dalam hal pengambilan keputusan, akibatnya bila ada informasi baru, proses penerimaannya lebih lambat (Albery \& Munafo, 2011). Orang dengan pendidikan yang lebih tinggi cenderung akan mudah menerima suatu perubahan, dan lebih terbuka akan adanya informasi. Keterbukaan ini akan membuat ibu lebih mudah mencari informasi melalui banyak media.

\section{Hubungan Persepsi Dengan Keikutsertaan Prenatal Yoga Pada Ibu Hamil}


Persepsi adalah proses menunjukkan ada hubungan yang pengorganisasian, penginterpretasian bermakna antara persepsi dengan terhadap rangsang yang diterima oleh keikutsertaan prenatal yoga pada ibu organisme atau individu sehingga hamil. Hubungan ini didukung dari merupakan sesuatu yang berarti dan tabulasi silang antara persepsi ibu hamil merupakan aktivitas yang intergrated dengan keikutsertaan prenatal yoga yang dalam diri individu (Sunaryo, 2013). Persepsi ibu hamil tentang prenatal yoga di Puskesmas III Denpasar Utara didapatkan $61,3 \%$ memiliki persepsi yang positif. Hal ini didukung oleh pernyataan bahwa sebagian besar dari responden setuju dengan pernyataan bahwa prenatal yoga sangat baik untuk kesehatan ibu hamil dan bayinya dan dapat melancarkan persalinan. Selain itu prenatal yoga dapat meningkatkan ikatan bathin antara ibu dan bayinya. Namun masih ditemukan persepsi yang menyatakan bahwa prenatal yoga dilakukan biaya mahal, padahal kenyataan di lapangan yaitu di Puskesmas III Denpasar Utara prenatal yoga dilakukan tanpa biaya.

Hasil uji hubungan antara persepsi ibu hamil tentang prenatal yoga dengan keikutsertaan melakukan prenatal yoga dengan analisa uji statistik Chi Square didapatkan $\mathrm{p}$ value $<0,001$ hal ini 
dengan nama proses kealaman atau proses fisik, merupakan proses ditangkapnya suatu stimulus oleh alat indera manusia. Tahap kedua, merupakan tahap yang dikenal dengan proses fisiologis, merupakan proses diteruskannya stimulus yang diterima oleh reseptor (alat indera) melalui sarafsaraf sensoris. Tahap ketiga, merupakan tahap yang dikenal dengan nama proses psikologik, merupakan proses timbulnya kesadaran individu tentang stimulus yang diterima reseptor. Tahap ke empat, merupakan hasil yang diperoleh dari proses persepsi yaitu berupa tanggapan dan perilaku. Persepsi ibu hamil tentang prenatal yoga dapat diperoleh dari pengalaman tentang kehamilan, tingkat pendidikan, lingkungan sekitar, media elektronik maupun cetak dan sebagainya.

\section{KESIMPULAN DAN SARAN}

\section{Simpulan}

Terdapat hubungan antara tingkat pendidikan dan persepsi dengan keikutsertaan prenatal yoga pada ibu hamil
Petugas Kesehatan disarankan untuk mempertahankan mutu pelayanan yang ada dan selalu meningkatkan pengetahuan ibu hamil tentang manfaat yoga pada kehamilan. Informasi hendaknya juga diberikan kepada suami atau keluarga lainnya sehingga akan membuat baik persepsi ibu hamil lebih baik dan dapat meningkatkan keaktifan mengikuti prenatal yoga.

Dengan adanya hasil penelitian ini disarankan untuk peneliti lain dapat menyempurnakan penelitian ini dengan melanjutkan penelitian yang sejenis dan hasil yang diperoleh dari penelitian ini dapat dijadikan dukungan untuk melakukan penelitian yang lebih luas.

\section{DAFTAR RUJUKAN}

Dahlan S. (2009). Besar sampel dan cara pengambilan sampel dalam penelitian kedokteran dan kesehatan. Jakarta: Salemba Medika

Depkes (2009), Rencana Pembangunan Jangka Panjang Bidang Kesehatan 2005-2025, Jakarta: Depkes RI

\section{Saran}


Gong $\mathrm{H}^{1}$, Ni $\mathrm{C}^{2}$, Shen $\mathrm{X}^{3}$, Wu $\mathrm{T}^{4}$, Jiang $\mathrm{C}^{5}$. Yoga for prenatal depression: a systematic review and metaanalysis. BMC Psychiatry. 2015 Feb 5;15:14. doi: 10.1186/s12888-015-0393-1.

Tersedia

dari:

https://www.ncbi.nlm.nih.gov/pu bmed/25652267

Hosmer DW, Lemeshow S. (2000). Applied logistic regression. Edisi ke-2. USA: John Wiley \& Sons, Inc

Jiang $\mathrm{Q}^{1}$, Wu $\mathrm{Z}^{2}$, Zhou $\mathrm{L}^{1}$, Dunlop $\mathrm{J}^{3}$, Chen P. (2015). Effects of yoga intervention during pregnancy: $a$ review for current status. Am J Perinatol. 2015 May;32(6):50314. doi: 10.1055/s-00341396701. Epub 2014 Dec 23. Tersedia dari: https://www.ncbi.nlm.nih.gov/pu bmed/25535930

Kawanishi $\mathrm{Y}^{1}$, Hanley SJ, Tabata K, Nakagi Y, Ito T, Yoshioka E, Yoshida T, Saijo Y.Effects of prenatalyoga: a systematic review of randomized controlled trials.Nihon Koshu Eisei Zasshi.
2015;62(5):221-31.

doi:

10.11236/jph.62.5_221. Tersedia dari:

https://www.ncbi.nlm.nih.gov/pu bmed/26118705
Kincer, Patricia. 2014. Yoga For Chronic Depressive Symptoms in Pregnancy: A Commentary and call to action. Virginia commonwealth university. School of nursing. Richmond. USA

Krisnadi, S. (2010). Sinopsis yoga untuk kehamilan: sehat, bahagia, dan penuh makna. http//www.bukukita.com Jakarta, diakses 23 September 2016

Nerendran, S. (2009). Yoga Improves Pregnancy Outcomes Source : Journal of Alternative and Complementary Medicine 2005; 11; 237-44. Diakses 11 Januari 2016

Narendra, S. 2009. Yoga impovs pregnancy outcomes source:Journal of alternative nd complementary medicine. 
Diaskes pada tanggal 4 maret 2016

Notoatmodjo, S. (2010). Ilmu perilaku kesehatan. Jakarta: Rineka Cipta. Notoatmodjo, S.(2012). Promosi kesehatan dan perilaku kesehatan. Jakarta: Rineka Cipta Pratignyo. 2014. Yoga Ibu Hamil. Depok : Pustaka Bunda

Rusmita, E. (2011). Pengaruh senam hamil yoga selama kehamilan terhadap kesiapan fisik dan psikologis dalam menghadapi persalinan pada ibu hamil trimester III di RSIA Limijati Bandung. Tesis, Universitas

Shindu, P. (2013). Panduan lengkap Yoga: Untuk hidup sehat dan seimbang. Bandung: PT Mizan Pustaka

Sugiyono. (2009). Statistika untuk penelitian. Edisi ke-15. Bandung: Alfabeta

Sugiyono. (2010). Metode penelitian kuantitatif, kualitatif dan $R \& D$. Edisi ke-9. Bandung: Alfabeta Sunaryo. (2013). Psikologi Untuk Keperawatan (Edisi 2.). Jakarta: EGC 